\title{
EL REFERÉNDUM SOBRE LA PERMANENCIA DE ESPAÑA EN LA OTAN
}

\author{
Juan Antonio Martínez Sánchez ${ }^{1}$ \\ Escuela de Suboficiales de la Armada
}

\begin{abstract}
Resumen:
En el presente artículo se hace una revisión histórica y cronológica del proceso de adhesión de España a la OTAN, proceso iniciado durante el primer Gobierno de la Unión de Centro Democrático (UCD) de Adolfo Suárez y que culminó con el referéndum celebrado el 12 de marzo de 1986, en el que el pueblo español refrendó la permanencia en dicha organización. En este proceso jugó un papel esencial el cambio de actitud del Partido Socialista Obrero Español (PSOE), desde la oposición radical a la adhesión hasta una postura favorable hacia la permanencia. En este trabajo se analizan las causas de dicho cambio de actitud, así como la postura y opinión ante la adhesión de diversos grupos y estamentos como los partidos políticos, la Iglesia, los medios de comunicación y la opinión pública.
\end{abstract}

Palabras clave: OTAN, UCD, PSOE, referéndum, España, adhesión.

\begin{abstract}
:
This article presents a chronological and historic overview of Spain joining NATO, a process which was initiated during the first government of the Union de Centro Democratico (UCD) under Adolfo Suarez. This process culminated with the referendum that took place on March 12, 1986, in which the Spanish people endorsed this organization. Throughout the process, the Spanish Socialist Workers' Party (PSOE) played an essential role as it went from radically opposing the process to taking a favorably stance in accepting it. The causes for a change in attitude and opinion towards the process by different groups and social classes, such as the church, media outlets and the public, will be analyzed throughout the paper.
\end{abstract}

Keywords: NATO, UCD, PSOE, referendum, Spain, adhesion.

Copyright (C) UNISCI, 2011.

Las opiniones expresadas en estos artículos son propias de sus autores, y no reflejan necesariamente la opinion de UNISCI. The views expressed in these articles are those of the authors, and do not necessarily reflect the views of UNISCI.

\footnotetext{
${ }^{1}$ Capitán (CMS-EO) Juan Antonio Martínez Sánchez. Licenciado en Psicología. Diplomado en Psicología Militar. Máster en Paz, Seguridad y Defensa. Ha sido profesor titular y jefe del Departamento de Ciencias Jurídicas y Sociales de la Academia General del Aire. En 2009 fue jefe del Servicio de Psicología del destacamento español de ISAF-OTAN en Herat, Afganistán. Actualmente es profesor asociado en la Escuela de Suboficiales de la Armada. Email: jamartsan@ea.mde.es.
} 


\section{Introducción}

Tras largas y duras negociaciones, el 24 de enero de 1976 se firmó la renovación de los acuerdos militares hispano-norteamericanos, establecidos inicialmente en $1953^{2}$. Congruente con la postura norteamericana, partidaria de la completa integración española en el sistema defensivo occidental, en la firma de dicha renovación se contemplaba una serie de medidas que encaminaban irremediablemente a nuestro país hacia la OTAN. Así, el artículo $1^{\circ}$ proponía la creación del Consejo Hispano-norteamericano, con la finalidad de desarrollar la coordinación con la Alianza Atlántica con vistas a una mejor contribución a la defensa de Occidente $^{3}$. Por otra parte, los artículos $5^{\circ}$ y $6^{\circ}$ abordaban la cooperación en materia de defensa, lo que permitía proporcionar la asistencia necesaria para que España desarrollara un papel activo en la defensa de Occidente y preparar de esa manera el camino para un adecuado ingreso de España en la OTAN ${ }^{4}$.

\section{Los gobiernos de UCD y el proceso de adhesión}

La firma del tratado de renovación de los acuerdos bilaterales creó las condiciones adecuadas para la integración española en la Alianza. Durante la exposición al Pleno de las Cortes de su programa de Gobierno el 28 de enero de 1976, el presidente Carlos Arias Navarro planteó la posibilidad de la adhesión al declarar que: “(...) se están considerando las alternativas posibles con la Organización del Tratado del Atlántico Norte, con el convencimiento de que la decisión que se adopte deberá contar con un análisis previo de los compromisos que nuestra eventual participación en los esquemas de dicha Alianza traería consigo"s.

El 1 de julio Arias Navarro presentó su dimisión a petición del Rey D. Juan Carlos I, quien nombró nuevo presidente del Gobierno a Adolfo Suárez dos días más tarde. Unos meses después, en septiembre, entraron en vigor los acuerdos bilaterales con Estados Unidos en materia de Defensa, produciéndose un impulso al proceso de adhesión a la Alianza, en el que desempeñó un papel fundamental el nuevo ministro de Exteriores Marcelino Oreja, y que se debió en buena parte a un aumento del interés de los Estados Unidos por el ingreso de España en esta organización ${ }^{6}$. Podemos citar a este respecto las manifestaciones de apoyo del secretario general de la OTAN Joseph Luns a diversas autoridades españolas, las reuniones celebradas entre el presidente del Comité Militar, almirante Hill-Norton, y el Jefe del Alto

\footnotetext{
${ }^{2}$ Para una descripción más detallada de estas negociaciones véase Powell, Charles T.: "Estados Unidos y España, de la dictadura a la democracia: el papel de Henry A. Kissinger (1969-1977)", en Powell, Charles T. y Jiménez, Juan C. (eds.) (2007): Del autoritarismo a la democracia. Estudios de política exterior española, Madrid, Sílex, pp. 19-71.

${ }^{3}$ Arenal, Celestino del y Aldecoa, Francisco (1984): España y la OTAN. Textos y documentos, Madrid, Tecnos, p. 213; Wojna, Beata (2004): La política de seguridad en España y Polonia en la transición hacia la democracia: un análisis comparado. Tesis doctoral. Madrid, Universidad Complutense, p. 237.

4 "Report of the Department of State, February 6, 1976", The Department of State Bulletin, March 22, 1976, pp. 362-364.

5 Aldecoa, Francisco: "Significado y efectos de la adhesión de España a la Alianza Atlántica en su proceso de participación activa en las relaciones internacionales", Revista de Estudios Internacionales, vol. IV, $\mathrm{n}^{\circ} 1$ (eneromarzo 1983), p. 52.

${ }^{6}$ Marquina, Antonio (1986): España en la politica de seguridad occidental. 1936-1986, Madrid, Ediciones Ejército, p. 899.
} 
Estado Mayor español, teniente general Fernández Vallespín; o la publicación de diversos artículos sobre el tema en la prensa especializada norteamericana ${ }^{7}$.

Sin embargo, ante las reticencias de países aliados como Noruega, Dinamarca, Holanda y el Reino Unido, que cuestionaban que España hubiera alcanzado la madurez democrática necesaria para su adhesión a la OTAN, el gobierno español puso en marcha una estrategia de acercamiento a la organización con el objetivo de obtener el respaldo general a una eventual solicitud de ingreso. Así, el 9 de noviembre de 1976, una delegación española del Centro Superior de Estudios de la Defensa Nacional (CESEDEN) visitó varias instalaciones de la Alianza en Europa, siendo recibida por el comandante en jefe de las fuerzas militares (SACEUR, Mando Supremo Aliado en Europa), el general norteamericano Alexander Haig. Fruto de este acercamiento fue también la puesta en marcha de un comité para el estudio de la cooperación con la organización, así como la implantación en la Escuela Superior del Ejército de un curso sobre la OTAN.

Esta aproximación pareció dar sus frutos, y el 10 de diciembre la OTAN manifestó su disposición a admitir a nuevos miembros. En enero de 1977 el secretario general Luns declaraba ante periodistas españoles la conveniencia de que España se integrase en la OTAN, declaración apoyada poco después por el vicepresidente norteamericano Walter Mondale. Esta actitud favorable a la adhesión comenzó a chocar con la postura ambigua del presidente Suárez, más preocupado por las cuestiones de política interior que por las de exterior, dada la fragilidad de la joven democracia española. Ello le llevó por un lado a realizar manifestaciones contrarias a la integración; y por otro a intentar allanar el camino de cara al posible ingreso. Como ejemplo de lo primero, en una entrevista celebrada con el presidente norteamericano James Carter en Washington el 29 de abril, Suárez rechazó la adhesión por considerarla en aquel momento contraproducente para la situación interna española. A pesar de ello, el presidente puso en marcha una política de acercamiento a la organización, que se reflejó en varios aspectos:

a) El establecimiento de contactos formales con representantes de la Alianza, como los realizados por el entonces embajador en Bruselas, Nuño Aguirre de Cárcer, con el secretario general y con el presidente del Comité Militar, en enero y febrero de 1977 respectivamente.

b) La elaboración por el Ministerio de Asuntos Exteriores de las directrices respecto al debate sobre la OTAN, con énfasis en el carácter europeo de la relación EspañaOTAN y en la necesidad de incluir la cuestión de Gibraltar dentro de las negociaciones para la adhesión.

c) La unificación, mediante el Real Decreto 1558, de 4 de julio de 1977, de los tres ministerios militares en el Ministerio de Defensa, lo que equiparaba este Ministerio con los de los países de la OTAN.

d) Los informes de la Dirección General de América del Norte y Pacífico, que subrayaban la implicación de España en la defensa de occidente a través de los acuerdos con los Estados Unidos y desaconsejaban las fórmulas neutralistas por desestabilizadoras del status quo existente en Europa, status que según dichos informes se vería mínimamente afectado por la entrada de España en la OTAN.

\footnotetext{
${ }^{7}$ Véase: Rivero, Horacio: "Spain: Free World Asset”, Strategic Review (spring 1976); Komorowski, Raymond A.: Spain and the Defense of NATO, U.S. Naval Institute Proceedings (may 1976).
} 
El 15 de junio de 1977 se celebraron las primeras elecciones democráticas en España. Conforme con la línea de ambigüedad señalada anteriormente, en el programa electoral de UCD se hacía mención de la necesidad e importancia de que nuestro país aceptara sus responsabilidades en la defensa de Occidente, aunque sin mencionar en concreto a la OTAN ${ }^{8}$. Sí lo hizo Suárez el 11 de julio en la Declaración de su Programa de Gobierno, en el que definió los objetivos de la política exterior española, incluyendo la integración en la CEE y otras instituciones europeas y la apertura de un debate político con vistas a la posible adhesión a la Alianza ${ }^{9}$.

Como vemos, el ingreso en la OTAN se planteaba como objetivo a conseguir, aunque ello requería un adecuado acuerdo parlamentario que preservara el frágil consenso político existente. Sin embargo, las notables diferencias entre Suárez y el ministro Oreja en cuanto a la estrategia y temporización a seguir para ello acabó obstaculizando gravemente la adhesión y provocando tensiones entre ambos. Mientras el presidente se mostraba extremadamente cauto, para el ministro la adhesión a la OTAN era requisito imprescindible en el proceso de integración en el bloque occidental, que además ofrecía innumerables ventajas a nuestro país, incluyendo el refuerzo de la seguridad nacional, la defensa de los intereses nacionales y la mejora de la defensa nacional en general, y de las Fuerzas Armadas en particular. Esos fueron los argumentos que utilizó Oreja en un discurso sobre política exterior pronunciado en el Senado el 9 de marzo de 1978, en el que manifestó el rechazo del Gobierno a cualquier tipo de neutralidad política y defendió la adhesión a la Alianza, planteando la conveniencia de un debate nacional como fórmula adecuada para ello ${ }^{10}$.

La celebración del I Congreso Nacional de UCD en octubre de 1978 supuso la confirmación del apoyo del partido al ingreso en la OTAN, al establecerse en sus conclusiones que "UCD es partidaria de la entrada de España en la OTAN en la forma y con las modalidades que más convengan a nuestros intereses" "1. Poco después, este tema quedó en segundo plano como consecuencia de la necesidad de lograr un consenso entre todos los partidos políticos para sacar adelante el texto de la Constitución.

Tras la aprobación en referéndum de la Constitución en diciembre, y de cara a las elecciones generales de marzo de 1979, UCD volvió a mostrarse partidaria en su programa electoral del ingreso. Esta postura fue ratificada por Suárez en su Discurso de Investidura del 30 de marzo, supeditándola a la obtención de un amplio respaldo parlamentario y a la necesidad de que se consideraran las particularidades y exigencias de la defensa del país.

A pesar de esta declaración de intenciones, durante la segunda legislatura de UCD persistió la política de ambigüedad del presidente, con alternancia de actos y declaraciones a favor y en contra de la adhesión. Por un lado, Suárez alentó la participación de España como país observador en la VI Cumbre de Jefes de Estado y de Gobierno de los Países No Alineados, celebrada en La Habana en septiembre de 1979, y en la que Fidel Castro, en su discurso inaugural, alabó públicamente la postura española por no dejarse manejar por la

\footnotetext{
8 Puente, Guillermo: "España en la Alianza Atlántica: el proceso político de su incorporación", Foro Internacional, vol. XLIII, $\mathrm{n}^{\circ} 2$ (abril-junio 2003), p. 323.

${ }^{9}$ Aldecoa, op. cit., p. 53; Arenal et al., op. cit., p. 215.

${ }^{10}$ Arenal et al., op. cit., pp. 218-219.

${ }^{11}$ Calvo-Sotelo, Leopoldo, y del Campo, Salustiano: Sobre la transición exterior. Discurso de recepción del Académico de Número Excmo. Sr. D. Leopoldo Calvo-Sotelo Bustelo, Marqués de la Ría de Ribadeo: sesión del día 16 de noviembre de 2005. Madrid, Real Academia de Ciencias Morales y Políticas, 2005, p. 65.
} 
OTAN y por mantenerse independiente ante el imperialismo norteamericano ${ }^{12}$. Por otra parte, en abril de 1980 se firmó la Directiva de Defensa Nacional 01/80, en la que se propugnaba una integración en la Alianza dados los beneficios que ello tendría para nuestra política de defensa.

La ambigüedad o indefinición de Suárez sobre el ingreso en la OTAN ha sido justificada por algunos autores en base a un supuesto antinorteamericanismo y sentimiento nacionalista, herencia de su pasado franquista ${ }^{13}$. Para otros autores ello se debía a factores como la escasa importancia que el presidente concedía a las cuestiones estratégicas internacionales ${ }^{14}$ o su mayor interés en las relaciones con Iberoamérica ${ }^{15}$. No obstante, una explicación más coherente radica en la importancia extrema que Suárez concedía a la política interior de cara a la consolidación de un sistema político democrático, y en su temor a que un desacuerdo profundo en política exterior pusiese en peligro el frágil consenso existente en ese momento histórico entre los distintos grupos parlamentarios ${ }^{16}$. En este sentido, el Gobierno de UCD consideraba prioritario como objetivo en política exterior la adhesión a la CEE, una cuestión sobre la que sí había acuerdo entre todos los partidos políticos.

En la primavera de 1980 se produjo un acontecimiento de gran importancia, al vetar Francia el proceso de ampliación de la CEE, paralizándose la adhesión de España a dicha organización. A partir de ese momento, el Gobierno español comenzó a utilizar el ingreso en la OTAN como moneda de cambio para obtener la adhesión a la CEE. En este contexto el ministro Oreja realizó en junio unas declaraciones al periódico El País en las que manifestaba que el Gobierno era totalmente "favorable a la pronta incorporación a la Alianza Atlántica" bajo dos condiciones: a) obtener garantías de que proseguirá el proceso de integración en la CEE, y b) impulsar la negociación para el traspaso de la soberanía de Gibraltar a España ${ }^{17}$. En estas declaraciones el ministro fijó como fecha para el debate político 1981, año en que expiraba el tratado bilateral con los Estados Unidos.

A los problemas que había supuesto para el Gobierno el veto francés hay que sumarles las dificultades por las que se atravesaba en política interior, a raíz de la moción de censura presentada por el PSOE en mayo de 1980 y del fuerte castigo recibido por UCD en las primeras elecciones autonómicas de Cataluña y el País Vasco. A ello se añadían también las divergencias existentes entre Suárez y Oreja, acrecentadas tras las declaraciones realizadas por el ministro a El País, y que culminaron el 3 de septiembre con su destitución y sustitución por José Pedro Pérez Llorca, quien paradójicamente siempre había mostrado una clara vocación atlantista.

A finales de 1980 todo parecía preparado para la celebración del debate parlamentario sobre la adhesión, pero una vez más Suárez retrasó el momento, argumentando la fuerte oposición del PSOE y las consecuencias desestabilizadoras que ello tendría para la estabilidad interna del país. La actitud del presidente español comenzó a causar preocupación en los

\footnotetext{
${ }^{12}$ Rupérez, Javier (1986): España en la OTAN. Relato Parcial, Madrid, Plaza \& Janés, p. 87.

${ }^{13}$ Val Cid, Consuelo del (1996): Opinión pública y opinión publicada. Los españoles y el referéndum de la OTAN, Madrid, Centro de Investigaciones Sociales \& Siglo XXI de España editores.

${ }^{14}$ Bray, Nicholas: “España-Estados Unidos: las bases”, Politica Exterior, II (5) (invierno 1988), p. 175.

15 Arenal, Celestino (1994): La política exterior de España hacia Iberoamérica, Madrid, Ediciones Complutense; citado por Wojna, op.cit., p. 233.

${ }^{16}$ Rodrigo, Fernando: “La inserción de España en la política de seguridad occidental”, en Gillespie, Richard; Rodrigo, Fernando y Story, Jonathan (eds.) (1996): Las relaciones exteriores de la España democrática, Madrid, Alianza, pp. 77-103.

${ }^{17}$ Sebastián, Pablo: "Marcelino Oreja: «Podemos adherirnos a la OTAN en corto plazo», El País, 15 de junio de 1980, p. 18.
} 
Gobiernos aliados, así como graves disensiones en el seno de UCD, acentuando el clima de crisis interna existente que culminó con el denominado movimiento crítico, encabezado por Miguel Herrero de Miñón y que jugó un papel crucial en el II Congreso del partido, celebrado en Palma de Mallorca en febrero de 1981. En las ponencias de dicho Congreso se volvió a destacar la importancia de la Alianza ante el empeoramiento de la situación internacional, sugiriéndose la necesidad de que España perteneciera a ella ${ }^{18}$.

Acosado tanto dentro como fuera de su partido y viendo cercano el fin de su Gobierno, Suárez tomó dos decisiones de gran importancia. En primer lugar, tras informar al Rey, al vicepresidente Gutiérrez Mellado y al ministro Pérez Llorca, el 23 de enero de 1981 comunicó al diputado Javier Rupérez y al ministro de Exteriores belga, Leo Tindemans, su decisión de integrar a España en la OTAN ${ }^{19}$. Apenas unos días más tarde - el 27 de enero- Suárez presentó su dimisión al Rey.

Desde un principio, el gobierno de Calvo Sotelo adoptó una postura claramente favorable al ingreso en la Alianza. En su discurso de investidura ante el Congreso de los Diputados el 18 de febrero de 1981, el presidente reafirmó la vocación atlántica del nuevo Ejecutivo, "expresamente manifestada por la Unión de Centro Democrático" y declaró su voluntad de "(...) iniciar las consultas con los grupos parlamentarios a fin de articular una mayoría, escoger el momento y definir las condiciones y modalidades en que España estaría dispuesta a participar en la Alianza" ${ }^{20}$.

Las palabras del recién nombrado presidente suscitaron fuertes críticas entre los grupos parlamentarios de la izquierda y constituyeron el punto de partida de la campaña antiOTAN que se desató en los meses posteriores ${ }^{21}$. La decisión de incorporar España a la OTAN ha sido calificada por algunos autores de gratuita, irreflexiva, apresurada o inoportuna ${ }^{22}$. No obstante, esta medida parece haber sido suficientemente meditada por el presidente y motivada por varios factores, a saber:

$1^{\circ}$. En primer lugar, para poner fin a la ambigüedad que había caracterizado a los gobiernos de Suárez ${ }^{23}$ y, como Calvo Sotelo declaró en su discurso de investidura, por coherencia con su concepción general de la política española y como medio de salvaguardar las necesidades defensivas y de seguridad ${ }^{24}$.

$2^{\circ}$. La mayor importancia que otorgaba a una política exterior de corte pro occidental, así como su conciencia de la estrecha relación existente entre la integración en la OTAN y la adhesión a la $\mathrm{CEE}^{25}$.

\footnotetext{
${ }^{18}$ Aldecoa, op.cit., pp. 59-60.

${ }^{19}$ Sarasqueta, Antxon (1985): Después de Franco, la OTAN, Barcelona, Plaza \& Janés, p. 44.

${ }^{20}$ Programa de Gobierno de Calvo Sotelo. Diario de Sesiones del Congreso de los Diputados, $\mathrm{n}^{\circ} 143,18$ de febrero de 1981, pp. 9156-9157.

${ }^{21}$ Calvo Sotelo y del Campo, op. cit., p 68.

${ }^{22}$ Arenal, Celestino del: "La posición exterior de España", en Cotarelo, Ramón (ed.) (1992): Transición politica y consolidación democrática. España (1975-1986), Madrid, Centro de Investigaciones Sociológicas, p. 414.

${ }^{23}$ Powell, Charles T. "Leopoldo Calvo Sotelo: corrigiendo el rumbo de una democracia amenazada", Revista de Occidente, no 336, 2009, p. 50.

${ }^{24}$ Programa de Gobierno de Calvo Sotelo, op. cit.

${ }^{25}$ La relación entre la adhesión a la OTAN y el ingreso en la CEE es defendida también por el que fuera primer embajador de España en la OTAN, Javier Rupérez: "Cuando entramos en la OTAN...", Revista española de defensa, Madrid, Ministerio de Defensa, DRISDE, nº 112 (junio 1997), p. 18. Esta opinión no es compartida sin embargo por Ángel Viñas, quien sostiene que la necesidad de europeizar España fue en realidad una excusa que escondía las motivaciones políticas de la decisión, y que la adhesión al Tratado de Washington no impulsó el
} 
$3^{\circ}$. La necesidad de reformular las relaciones bilaterales con los EEUU, unas relaciones desequilibradas y que eran mera prolongación de los acuerdos de 1953.

$4^{\text {o. }}$ Las numerosas conspiraciones golpistas y el fallido intento del 23 de febrero de 1981 hicieron patente la necesidad de modernizar las FAS para evitar futuras actuaciones antidemocráticas $^{26}$.

$5^{\circ}$. La certeza de que no iba a ser reelegido en las siguientes elecciones generales, dada la "autodestrucción irreversible" hacia la que se encaminaba la UCD, lo que le otorgaba una libertad de decisión que de otro modo no hubiera gozado. Este argumento, reconocido posteriormente por el mismo Calvo Sotelo ${ }^{27}$, se encontraba en la base de las críticas que recibió de la oposición, que veían tras la decisión de adhesión a la OTAN una política de hechos consumados, es decir, un intento de obligar al futuro gobierno socialista a aceptar una adhesión ya ejecutada, puesto que la salida de la OTAN tendría un grave coste político ${ }^{28}$.

Con todo, la incorporación de España a la OTAN tuvo que demorarse unos meses por el escepticismo y recelo que aún suscitaba en los países aliados el proceso democratizador español. En mayo, durante una visita a la República Federal de Alemania, Calvo Sotelo confirmaba el inmediato ingreso de España en la OTAN y su intención de no convocar un referéndum. A partir de entonces los acontecimientos se desarrollaron con celeridad.

El 20 de agosto de 1981 el Consejo de Ministros solicitó al Consejo de Estado el dictamen preceptivo sobre el ingreso de España en la OTAN, emitiendo éste dictamen favorable una semana más tarde y recomendando la vía del artículo 94.1 de la Constitución para su tramitación parlamentaria. Días más tarde, el 31 de agosto, el Gobierno presentó ante la Mesa del Congreso de los Diputados la solicitud para la autorización de adhesión a la OTAN, siendo admitida a trámite el 2 de septiembre con los votos en contra de socialistas y comunistas. El 15 de septiembre, el Pleno del Congreso de los Diputados decidió por 180 votos a favor, 126 en contra y 2 abstenciones, que la Comisión de Asuntos Exteriores era competente para tratar el proyecto de adhesión. Los debates en la Comisión se desarrollaron del 6 al 8 de octubre, con la participación de los representantes de todos los grupos parlamentarios y del ministro Pérez Llorca, quien en su intervención del 6 de octubre desechó la opción de la neutralidad y subrayó las ventajas de la integración en la Alianza, que ofrecía mayores garantías de seguridad y participación que los acuerdos bilaterales firmados hasta entonces con Estados Unidos ${ }^{29}$.

Pese a la oposición de socialistas y comunistas, el 8 de octubre la Comisión de Asuntos Exteriores aprobó el dictamen favorable a la adhesión. Este dictamen se debatió en el

lento proceso de incorporación a la CEE. Véase Viñas, Ángel: "Coordenadas de la política de seguridad española", Leviatán: Revista de hechos e ideas, n 17, 1984, p. 10.

${ }^{26}$ De esta última opinión son también Pérez Llorca, José P.: "De cómo y porqué entramos en la Alianza Atlántica”, Ideas para la democracia, n¹, 1984, Madrid, Cambio 16, p. 316; Puente, op. cit., p. 327; Rupérez, op. cit., p. 19; y Powell, 2009, op. cit., p. 51. Sin embargo, un informe elaborado en 1982 por Allan S. Nanes para el Congreso de los EEUU mostraba la ausencia de relación causa-efecto entre la incorporación de España a la OTAN y la reorientación política de sus FAS. Véase Viñas (1984), op. cit., p. 11.

${ }^{27}$ Calvo Sotelo y del Campo, op. cit., pp. 73-74.

${ }^{28}$ Powell, 2009, op. cit., p. 49.

${ }^{29}$ Diario de Sesiones del Congreso de los Diputados, Comisión de Asuntos Exteriores, octubre de 1981, $\mathrm{n}^{\circ} 41$, 42 y 43, pp. 1802-2048. 
Pleno del Congreso los días 27 a 29 de octubre, siendo aprobado con los 186 votos a favor de UCD, Coalición Democrática, Partido Nacionalista Vasco, Convergencia i Unió y Unión del Pueblo Navarro; por los 146 en contra del PSOE, Partido Socialista Andaluz, Partido Comunista de España, Euskadiko Ezkerra, Ezquerra Republicana de Catalunya, Partido Aragonés Regionalista y Unión del Pueblo Canario. En virtud de ello, el Gobierno quedaba autorizado para solicitar formalmente la adhesión a la OTAN con las siguientes condiciones:

a) No aceptar compromisos que implicasen el almacenamiento o instalación de armas nucleares de la Alianza en nuestro país.

b) Obtener garantías para la defensa de todo el territorio peninsular y extrapeninsular, la recuperación de la soberanía sobre Gibraltar y el impulso de las negociaciones para el ingreso en la CEE.

El 26 de noviembre, el Pleno del Senado ratificó la decisión del Congreso por 106 votos a favor, 60 en contra y una abstención, dejando libre el camino para la presentación de la solicitud de adhesión. Consecuentemente, el 2 de diciembre el embajador español en Bruselas Aguirre de Cárcer entregó oficialmente a Luns la carta por la que el Gobierno español se declara dispuesto a recibir la invitación de la Alianza y depositar, llegado el momento, el correspondiente instrumento de adhesión. El día 10 los ministros de Exteriores de los quince países aliados firmaron el Protocolo de Adhesión en una reunión ministerial del Consejo Atlántico en Bruselas, mostrando su satisfacción y resaltando el impulso que ello supondría para la Alianza ${ }^{30}$. A partir de ese momento se iniciaron los trámites de ratificación por los parlamentos de los países aliados, y España dedicó un esfuerzo considerable para convertirse en el miembro número dieciséis de la OTAN con la máxima rapidez posible, consiguiéndolo en apenas seis meses.

El 29 de mayo de 1982 Luns dirigió una carta al Gobierno español invitándole a adherirse a la Alianza. Ese mismo día, la Oficina de Información Diplomática del Ministerio de Asuntos Exteriores emitió el comunicado que anunciaba la entrega del Instrumento de Adhesión del Reino de España a la OTAN ${ }^{31}$. Apenas un día después, en una maniobra de anticipación a los obstáculos que el PSOE planteaba a la adhesión, el encargado de negocios en Washington, Álvarez de Toledo, entregó el documento de adhesión al vicesecretario norteamericano de Estado Walter Stressel, y España se convertía en el $16^{\circ}$ miembro de la OTAN $^{32}$. El 4 de junio se izaba la bandera española en el Cuartel General Militar del SACEUR, y 5 días después el presidente Calvo Sotelo asistía a la Cumbre de la OTAN en Bonn.

El 7 de julio, Javier Rupérez fue nombrado primer embajador en la OTAN, y comenzó a preparar las conversaciones preliminares para la integración española. En varias rondas de negociaciones, celebradas entre julio y octubre de ese año, se abordaron temas como las posibles amenazas para nuestro país, la participación en la estructura de mandos y el estado de

\footnotetext{
${ }^{30}$ Puente, op. cit., p. 309.

${ }^{31}$ Instrumento de adhesión del Reino de España al Tratado del Atlántico Norte, Boletín Oficial del Estado núm. 129, de 31 de mayo de 1982, pp. 14393-14394.

${ }^{32}$ El 28 de mayo de 1982 el PSOE había presentado con urgencia una proposición no de ley ante la Mesa del Congreso en la que solicitaba la suspensión de las negociaciones para la adhesión a la OTAN hasta que no quedara asegurada la soberanía de Gibraltar. Esta proposición no llegó a debatirse, ya que las Cortes se disolvieron al mes siguiente.
} 
preparación de las FAS españolas. Según el mismo Rupérez, estas conversaciones fueron intensas y complicadas debido a la urgencia española por completarla en un corto espacio de tiempo, dada la situación política interna del país ${ }^{33}$. Pesaba sobre el Gobierno la amenaza de la progresiva disolución de la UCD y del adelanto de las elecciones generales en la que las posibilidades de victoria eran escasas, como así ocurrió finalmente ${ }^{34}$. Fruto de esas conversaciones, España se unió a varios organismos aliados, como el Comité de Planes de Defensa, el Grupo de Planes Nucleares y el Comité Militar.

\section{EI PSOE y el proceso de adhesión}

La postura del PSOE con respecto al proceso de adhesión de España en la OTAN ha sido ampliamente criticada, calificándola -entre otros adjetivos- de incoherente, irresponsable, electoralista, manipuladora y, sobre todo, errónea.

Durante la transición, los posicionamientos socialistas en política de defensa tuvieron fuertes connotaciones neutralistas y antinorteamericanistas, como quedó reflejado en el XXVII Congreso del partido, celebrado en diciembre de 1976, y en el que se propugnó un modelo de neutralidad activa cuyos objetivos prioritarios eran el desmarque de la política de bloques militares y el desmantelamiento de todas las bases norteamericanas en territorio español. En diciembre de 1977, una delegación del PSOE formada por el secretario general del partido Felipe González, Alfonso Guerra, Miguel Boyer y Francisco Ramos visitó la Unión Soviética, invitados por el Partido Comunista ruso. El día 12, en una entrevista mantenida con el entonces secretario del Comité del Partido Comunista ruso y miembro del Buró Político, Mijail Susnov, González resaltó la vocación neutralista del PSOE y defendió que la decisión de la entrada de España en la OTAN correspondía al pueblo español y debía resolverse sin injerencias externas ${ }^{35}$. A pesar de ello, la delegación española aceptó el comunicado redactado por el PCUS y publicado en el diario Pravda, en el que se manifestaba que "las delegaciones han reafirmado los criterios de sus partidos acerca de la necesidad de superar la división del mundo contemporáneo en bloques político-militares contrapuestos, así como su ampliación" 36 . Este gesto fue interpretado por los medios informativos occidentales como un logro del gobierno ruso, interesado en conseguir que España no se incorporara a la OTAN.

Como refiere el mismo Calvo Sotelo, esta actitud neutralista y de no alineación, defendida igualmente por el Partido Socialista en su XXVIII Congreso de 1979, no era coherente con la adoptada por el PSOE en el exilio cuando se constituyó la Alianza en 1949. En aquel momento, el PSOE defendía firmemente la necesidad de que España se incorporara a la OTAN, una vez desaparecido el régimen franquista ${ }^{37}$.

Como consecuencia de los acercamientos del Gobierno de UCD a la Alianza, durante 1980 la política del PSOE se transformó claramente en antiOTAN. En marzo de ese año

\footnotetext{
${ }^{33}$ Rupérez, 1997, op. cit., p. 19.

${ }^{34}$ En agosto de 1982 Calvo Sotelo anunció el adelanto de las elecciones generales y su convocatoria para el 28 de octubre.

${ }^{35}$ López Muñoz, Ismael: "El PSOE aceptó en Moscú no apoyar el ingreso en la OTAN", El País, 17 de diciembre de 1977.

${ }^{36}$ Calvo Sotelo y del Campo, op. cit., p. 75.

${ }^{37}$ Ibid., pp. 63-64. Véase a este respecto Luxan, Adolfo de, y Puerta, Alonso J. (eds) "El socialismo español en el exilio y la construcción europea”, Madrid, Fundación Acción Socialista Europea-Fundación Indalecio Prieto, 2003.
} 
González hizo pública su postura a nivel internacional, al defender en el Congreso de la Unión de Partidos Socialistas Europeos la neutralización y desnuclearización del Mediterráneo, lo que entraba en clara contradicción con la esencia y existencia de la OTAN. Conforme avanzaban los contactos y acercamientos a la Alianza en 1981, la posición del PSOE se fue radicalizando. En el debate de investidura de Calvo Sotelo en febrero, González rechazó de lleno sus argumentos a favor del ingreso en la Alianza, aduciendo que se trataba de una organización al servicio de los intereses de Estados Unidos. En aquel discurso, el secretario general del PSOE hipotecó buena parte del futuro político de su partido al manifestar que si algún día llegaba al poder propondría la salida de la Alianza si el procedimiento de entrada no era un referéndum. En julio, ya tomada la decisión de ingresar en la OTAN, arreció la oposición socialista, que interpretaba la postura del gobierno como una "huida hacia adelante" que pretendía impedir el debate público al que UCD se había comprometido desde 1977 por temor a perderlo ${ }^{38}$. No obstante, en lugar de exigir un debate parlamentario para movilizar a la opinión pública, el PSOE se embarcó en una campaña demagógica y electoralista que pretendía movilizar a la opinión pública, utilizando el rechazo a la adhesión como arma política para atacar a la UCD y conseguir la victoria en las siguientes elecciones. Esta estrategia, que se desarrolló bajo el lema "OTAN, de entrada no", se plasmó en movilizaciones populares, campañas de recogida de firmas y declaraciones en la prensa, como las que realizó González al diario El País calificando el ingreso como "barbaridad histórica" y "tremendo error", y anunciando una campaña de oposición ${ }^{39}$; o las de Alfonso Guerra manifestando a Diario 16 que "el eventual ingreso en la OTAN convertiría a España en una Colonia de los Estados Unidos". Como consecuencia de la campaña anti-OTAN del PSOE, dirigida por Javier Solana, disminuyó considerablemente el porcentaje de partidarios de la adhesión, que pasó del $20 \%$ en julio de 1981 al $13 \%$ en septiembre de ese mismo año; en tanto que el porcentaje de partidarios del "no" aumentó del $35 \%$ al $43 \%{ }^{40}$.

El 3 de septiembre, un día después de que la Mesa del Congreso acordara la admisión a trámite parlamentario de la petición del Gobierno para la autorización de la adhesión, el PSOE presentó una moción solicitando la convocatoria de un referéndum, amparándose en el artículo 92 de la Constitución ${ }^{41}$. Del mismo modo, durante la celebración del posterior debate parlamentario sobre la OTAN en octubre de 1981, los socialistas introdujeron dos propuestas que tenían como objeto paralizar el ya irremediable proceso de adhesión: a) someter a consulta del Tribunal Constitucional una posible contradicción entre el texto del Tratado y la Constitución, y b) la realización de un referéndum sobre el tema. Ante el rechazo de estas propuestas, González manifestó al Congreso que el PSOE no se responsabilizaría de la decisión que estaba a punto de tomarse, atribuyendo dicha responsabilidad a los grupos que la apoyaban. Consecuentemente con esta actitud, el PSOE votó en contra de la adhesión tanto en el Congreso como en el Senado, basándose en los siguientes argumentos:

1. En primer lugar un sentimiento antinorteamericano, consecuencia de la imagen imperialista que se tenía de la política exterior de los EE.UU y fomentada por el apoyo norteamericano a la dictadura de Franco ${ }^{42}$. A ello había que añadirle un cambio de

\footnotetext{
${ }^{38}$ Powell, 2009, op. cit., p. 49.

39 Llorens, Isabel: “«Si España entra en la OTAN, soportaría la colonia de un aliado en territorio propio». Declaraciones de Felipe González”, El País, 26 de julio de 1981.

${ }^{40}$ Centro de Investigaciones Sociológicas: "La opinión pública española ante la OTAN", Revista Española de Investigaciones Sociológicas (REIS), nº 22 (abr./jun. 1983), pp. 219-226.

${ }^{41}$ Dicho artículo establece que "las decisiones políticas de especial trascendencia podrán ser sometidas a referéndum consultivo de todos los ciudadanos". Por su parte, el Gobierno de UCD se acogía al artículo 94, que limitaba el trámite de la firma de Tratados o convenios militares al consentimiento de las Cortes Generales.

${ }^{42}$ Yáñez, Luis (1984). “El PSOE y la seguridad europea, 1944-1984”, Ideas para la democracia, n 1, p. 325.
} 
opinión acerca de la guerra fría y del peligro que la amenaza soviética suponía para España, basado en un análisis más crítico y objetivo de la política soviética en Europa.

2. En segundo lugar, se argumentaba que la Alianza no tenía en cuenta los intereses españoles en Gibraltar ni asumía la defensa de Ceuta y Melilla, aduciéndose que el norte de África, posible zona de amenaza para España, quedaba excluido del área de aplicación del Tratado de Washington ${ }^{43}$.

3. El temor a que el ingreso en la OTAN ocasionara un desequilibrio en el balance estratégico entre los bloques militares. No hay que olvidar en este sentido el memorándum que el encargado de negocios de la embajada soviética había entregado al Gobierno español el 7 de septiembre de 1981, víspera del debate parlamentario sobre la OTAN, y en el que se advertía que la entrada de España en la OTAN provocaría un aumento de la tensión internacional, reforzaría la política de bloques e impulsaría la carrera de armamento. La respuesta del gobierno español fue no darse por enterado y devolver el documento a la embajada soviética ${ }^{44}$.

4. En último lugar, el ingreso en la OTAN convertiría a España en un objetivo potencial para el Pacto de Varsovia, con el consiguiente aumento del riesgo de sufrir un ataque nuclear.

Durante el XXIX Congreso, celebrado en octubre de 1981, González volvió a comprometerse a la realización de un referéndum consultivo cuando el PSOE accediera al Gobierno. En este Congreso se elaboró además un documento titulado "50 preguntas sobre la OTAN", que recalcaba las repercusiones negativas de la incorporación a la Alianza:

a) La OTAN no era garantía para la joven democracia española, tal como lo demostraba la presencia en la organización de regímenes totalitarios como Grecia y Turquía.

b) Tampoco garantizaba el ingreso en el Mercado Común.

c) Incremento notable de los gastos militares.

d) Nuclearización del país.

e) La entrada en la OTAN no implicaría la devolución de la soberanía sobre Gibraltar.

Como vemos, el PSOE se iba comprometiendo paulatinamente a una no integración de la que más tarde tendría que dar marcha atrás a expensas de importantes costes políticos.

\section{EI PSOE en el Gobierno}

\footnotetext{
${ }^{43}$ En este sentido resulta muy interesante las observaciones que Fernando Morán hace al respecto y que se recogen en Burns, Tom (1996): Conversaciones sobre el socialismo, Barcelona, Plaza \& Janés, pp. 337-357.

${ }^{44}$ Calvo Sotelo y del Campo, op. cit., p. 74.
} 
Durante la campaña electoral de 1982 el PSOE se comprometió a detener la integración en la OTAN y convocar un referéndum en caso de obtener la victoria. Esta postura era consecuente con las directrices adoptadas en el XXIX Congreso y se materializó en la presentación de numerosas propuestas y mociones cuyo objetivo era paralizar el proceso. Sin embargo, dicha cuestión quedó en un segundo plano en el programa electoral, incluyéndose dentro de un paquete de medidas en política exterior junto con otros objetivos como la adhesión a la CEE, el desarrollo de las relaciones internacionales con los países de Iberoamérica y del Magreb y la reformulación de las relaciones bilaterales con Estados Unidos.

Se ha aducido para justificar este supuesto "olvido" que Felipe González era consciente antes de ganar las elecciones de 1982 de las dificultades e inconvenientes que plantearía una eventual salida de la OTAN, lo que también explicaría el nombramiento de un proatlantista convencido como Narcís Serra al frente del Ministerio de Defensa en $1981^{45}$. Abandonar la Alianza hubiera sido interpretado por el resto de Europa Occidental como una falta de solidaridad que hubiera afectado negativamente la credibilidad española y perjudicado su ingreso en la CEE. Por otra parte, la alternativa al ingreso -la neutralidad o no alineamiento-, suponía una incongruencia con el tan preconizado europeísmo de la política exterior del PSOE, ya que compartir el destino político y económico europeo implicaba también asumir sus cargas defensivas. Por otra parte se ha argumentado que el PSOE había experimentado una transformación en sus planteamientos en política de defensa a consecuencia de los cambios producidos en el entorno geoestratégico internacional ${ }^{46}$.

Tras la victoria en las elecciones generales del 28 de octubre de 1982, el primer Gobierno socialista -formado el 3 diciembre- se encontró con una comprometida herencia de UCD. Calvo Sotelo había incorporado a España en la OTAN sin una definición clara y precisa de cómo se realizaría dicho proceso y con la mayoría de los partidos políticos y de la opinión pública en contra ${ }^{47}$. Para entonces los representantes españoles, encabezados por el embajador Rupérez, y los de la Alianza, al mando del secretario general adjunto de la Organización para asuntos políticos, David Nichols, habían esbozado en apenas cinco meses y tres rondas de conversaciones los principios básicos de entendimiento para la integración. Estos principios contemplaban, entre otras medidas, la inclusión de nuestro país en el Mando Aliado en Europa (ACE), la asignación de fuerzas españolas al SACEUR, el compromiso español en la defensa de toda la organización y el reconocimiento de la importancia del eje BalearesEstrecho de Gibraltar-Canarias ${ }^{48}$.

En una reunión del Consejo Atlántico celebrada en Bruselas el 8 de diciembre, el ministro de Exteriores socialista Fernando Morán anunció a los aliados la intención del nuevo Gobierno de paralizar el proceso de integración en la OTAN mientras se realizaba un análisis de los intereses estratégicos de España, supeditando la permanencia a la celebración de un referéndum. A partir de entonces, nuestro país continuó formando parte de la organización como miembro de pleno derecho, pero adoptando una posición pasiva que solo rompió para

\footnotetext{
${ }^{45}$ Conversación mantenida por Tom Burns con el exministro Narcís Serra. En Burns, op. cit., p. 191.

${ }^{46}$ Viñas (1984), op. cit., p. 17.

${ }^{47}$ Según datos del CIS, op. cit., p. 231, en abril de 1982 sólo un $17 \%$ de la población era partidario de seguir dentro de la OTAN.

${ }^{48}$ Resulta significativo el comentario realizado al respecto por el entonces embajador en la OTAN, Javier Rupérez: “(...) con unos pocos meses más de tiempo y en una situación política relativamente estable, la integración española en la Alianza se habría realizado felizmente y a satisfacción de todos”. Rupérez, op. cit., p. 20.
} 
defender los intereses nacionales ${ }^{49}$. La postura del Gobierno se ajustaba al compromiso electoral del PSOE y a la voluntad de la sociedad española, mayoritariamente en contra de la pertenencia de España en la Alianza ${ }^{50}$. Sin embargo, existía una contradicción latente entre su vocación europeísta y occidental y sus tendencias neutralistas, contradicción que se vio reflejada en una estrategia política conocida como ambigüedad calculada y que se caracterizó por la alternancia de declaraciones y actos a favor y en contra de la integración militar. De este modo, mientras por un lado se decidía mantener la presencia militar y diplomática en los comités de la OTAN, por otro se negaba a la nuclearización del territorio español en el Convenio Bilateral con los EEUU. Esta estrategia causó tensiones y enfrentamientos tanto entre la base y la cúpula del partido como dentro del propio Gobierno, ocasionadas por diversas corrientes de opinión:

$1^{\circ}$. De una parte, diplomáticos como Luis Yánez, ministros como José María Maravall, Ernest Lluch o Javier Solana y el mismo vicepresidente Alfonso Guerra estaban dispuestos a abandonar la Alianza y a orientar la política exterior española hacia una línea más neutralista y de cooperación con Iberoamérica y el tercer mundo. Muestra de la oposición del vicepresidente fueron sus declaraciones al diario El País en julio de 1983 en las que criticaba a algunos miembros del Gobierno por cambiar sus opiniones sobre la permanencia en la Alianza y en las que afirmaba textualmente: "Yo creo que España no debe estar en la OTAN, debe salir" ${ }^{, 51}$.

$2^{\circ}$. Por otro lado, el ministro de Defensa Narcís Serra se mostraba partidario de la permanencia en función de las ventajas y posibilidades que ello suponía para la industria española y la profesionalización de las FAS. Idéntica postura adoptaba el ministro de Economía Miguel Boyer, basándose en la contradicción que suponía una política económica europeísta y otra defensiva de carácter neutral.

$3^{\circ}$. Finalmente, otros miembros del Gobierno como el ministro Moran intentaron hallar una posición intermedia entre los postulados ideológicos y los intereses de estado.

Lenta y hábilmente, el presidente González fue desmarcándose de la posición inicial de su partido, llegando incluso a manifestar a la prensa que no era antiOTAN ${ }^{52}$ y demostrándolo con declaraciones de apoyo al despliegue de los misiles pershing II y cruise (euromisiles) realizadas en marzo de 1983 en la República Federal de Alemania ${ }^{53}$. Como es de suponer, esta actitud chocó con la postura de parte del Ejecutivo socialista y se encontraría en la base de la tormenta interna que iba a sacudir al partido años más tarde.

En 1983 el Ministerio de Asuntos Exteriores elaboró un informe sobre la OTAN, boceto del famoso Decálogo de política exterior que González presentaría al Congreso un año más tarde, y que recogía los siguientes puntos:

\footnotetext{
${ }^{49}$ Ortiz, Román D.: "El decimosexto aliado", Revista española de defensa, Madrid, Ministerio de Defensa, DRISDE, no 60 (febrero 1993), p. 60.

${ }^{50}$ Según datos del CIS, op. cit., p. 235, en marzo de 1983 un $57 \%$ de la población se mostraba poco o nada partidario de la plena integración, frente al $13 \%$ que era muy o bastante partidario de ello.

${ }_{51}$ Jáuregui, Fernando: "Entrevista con el vicepresidente, Alfonso Guerra: «Yo creo que España no debe estar en la OTAN, debe salir»", El País, 17 de julio de 1983.

${ }_{53}$ Declaraciones realizadas al periódico Diario 16 y recogidas en Val Cid, op. cit., p. 94.

${ }^{53}$ En este sentido, para Rupérez, 1997, op. cit., p. 18, las conversaciones mantenidas entonces entre González y el canciller alemán Helmult Kohl marcaron un punto de inflexión en el cambio de actitud y postura del presidente español.
} 
- Definición precisa de los criterios de no integración en la estructura militar.

- Declaración de no admisión, almacenamiento o tránsito de armamento nuclear en territorio español.

- Mantenimiento de las relaciones bilaterales con Estados Unidos, aunque con reducción de la presencia militar en España.

- Declaración a favor de la paz, la distensión y el desarme controlado y verificable.

En 1984 se produjo el definitivo giro atlantista en las manifestaciones de González y del resto de los miembros del gabinete socialista, incluyendo al vicepresidente Guerra, sucediéndose las declaraciones favorables en los medios de comunicación y enfatizándose la relación entre la permanencia en la OTAN y la integración en la CEE. Los días 23 a 25 de octubre se celebró el Debate sobre el Estado de la Nación, en el que Felipe González expuso ante el Congreso de los Diputados un proyecto global de política de paz y seguridad, cuyos principales objetivos eran servir adecuadamente a los intereses nacionales, contribuyendo eficazmente a la paz y a la distensión mundial, completar la incorporación de España a Europa a través de la participación en la seguridad colectiva, y superar la división existente en esa materia tanto entre las fuerzas políticas como la opinión pública. Dicho proyecto incluía su famoso "Decálogo", compuesto por una serie de puntos encaminados a la búsqueda del consenso en política exterior:

1. Permanencia en la OTAN.

2. No integración en la estructura militar.

3. Reducción de la presencia norteamericana en España.

4. No nuclearización.

5. No exclusión de la firma del Tratado de No proliferación Nuclear.

6. Voluntad de participación en la Unión Europea Occidental.

7. Recuperación de Gibraltar.

8. Continuación de los trabajos en la Conferencia Europea de Desarme.

9. Desarrollo de convenios bilaterales de cooperación defensiva con otros países de Europa occidental.

10. Elaboración del Plan Estratégico Conjunto ${ }^{54}$.

\footnotetext{
${ }^{54}$ Discurso del presidente del Gobierno, Felipe González, en el Debate sobre el Estado de la Nación, Diario de Sesiones del Congreso de los Diputados, no 157, de 23 de octubre de 1984, pp. 7070-7092. Un resumen del contenido del Decálogo puede ser consultado en: Vaca, Ana: "Las directrices cierran el «Decálogo»", Revista española de defensa, Madrid, Ministerio de Defensa, DRISDE, no 10 (diciembre 1988), p. 7; Gaitero, Javier M.: "España en la OTAN: crónica de una larga marcha", Revista española de defensa, Madrid, Ministerio de Defensa, DRISDE, no 4 (junio 1988), pp. 52-53.
} 
En su intervención parlamentaria, González expuso las líneas maestras de su política en relación con la Alianza: permanencia vinculada al ingreso en la CEE, oferta de diálogo a las fuerzas políticas parlamentarias con vistas a la consecución de un adecuado consenso y anuncio de la celebración de un referéndum para principios de 1986. El compromiso de celebrar un referéndum se justificaba por congruencia con las promesas electorales y por la necesidad de disponer del tiempo necesario para involucrar y responsabilizar a las distintas fuerzas políticas en una decisión trascendental como aquella e intentar cambiar la opinión contraria de buena parte del electorado ${ }^{55}$.

Decidida y clarificada definitivamente su actitud con respecto a la OTAN, González se dedicó hábil y eficazmente a la búsqueda de apoyo para sus tesis en el XXX Congreso del PSOE, celebrado en diciembre de 1984. Allí defendió la permanencia en la Alianza, aduciendo argumentos tan variados como la memoria histórica del partido, que en 1949 había valorado positivamente la creación del Pacto Atlántico; o la crítica al romanticismo e idealismo de la izquierda socialista por su actitud neutralista. En el mismo sentido, en las conclusiones del Congreso se aportaron otros argumentos contrarios a la salida de la OTAN, como no comprometer el proyecto global de construcción europea, no poner en entredicho la credibilidad exterior española y no afectar la estabilidad política de la organización. Finalmente, se reafirmaba la conveniencia de celebrar un referéndum "en la fecha que el Gobierno estime más oportuna, en función de las circunstancias nacionales e internacionales" $" 56$.

Esta toma de posición fue apoyada inicialmente por el Departamento de Estado norteamericano y por los países miembros de la OTAN, que acogieron positivamente estas medidas. Sin embargo, durante el año 1985 se produjeron varios hechos que transformaron esta euforia en preocupación. En política exterior, Estados Unidos se negó a negociar el tema de las bases hasta que España se comprometiera a permanecer en la Alianza; recibiéndose además presiones del Congreso de la Unión Europea Democristiana a favor de la adhesión. A nivel interno es de destacar la movilización popular encabezada por el PCE contra la OTAN mediante manifestaciones, declaraciones y actuaciones de las denominadas Mesas por el referéndum. Estas presiones volvieron a originar tensiones en el seno del Gobierno, y en julio Moran fue cesado en su cargo y sustituido por Francisco Fernández Ordóñez, de vocación mucho más atlantista que su predecesor ${ }^{57}$.

\footnotetext{
${ }^{55}$ Puente, op. cit., p. 335.

${ }^{56}$ Ibid., p. 336.

${ }^{57}$ Como causa del cese de Morán se han argumentado diversos motivos, incluyendo la necesidad de dar un nuevo aire al Ministerio de Exteriores en el nuevo contexto que suponía la reciente entrada en la Comunidad Europea, las malas relaciones y discrepancias de actitud respecto a la cuestión de la OTAN con Felipe González, o el deseo de éste de situar al frente de la diplomacia española a alguien capaz de encarar el próximo referéndum sobre la permanencia en la Alianza con "mayor credibilidad". Véase Viñas, Ángel: "Dos hombres para la transición externa: Fernando Morán y Francisco Fernández Ordóñez”, Historia Contemporánea, $\mathrm{n}^{\circ} 15$, 1984, pp. 273-274.
} 


\section{La campaña del referéndum sobre la permanencia en la OTAN}

En abril de 1985 González fijó el mes de marzo de 1986 como fecha para la celebración del referéndum $^{58}$, aunque sin aclarar su carácter vinculante o consultivo. A partir de ese momento se desató una intensa movilización política y popular que enrareció el ambiente del país, con la multiplicación de artículos de opinión desde todos los ámbitos de la sociedad española y la publicación de numerosos sondeos que reflejaban la opinión de los españoles.

El 3 de noviembre de 1985, apenas cinco meses antes del referéndum, El País publicó los resultados de un sondeo realizado entre los días 19 al 22 de octubre que indicaban que el $63 \%$ de los españoles deseaban el referéndum y que el $46 \%$ de los encuestados era partidario de la salida ${ }^{59}$. El riesgo de derrota era alto, lo que obligó al Gobierno a movilizarse de cara a la campaña electoral. Como dijo irónicamente Aguirre de aquel momento de nuestra historia: "El PSOE, utilizando todos los argumentos -desde las supuestas ventajas tecnológicas hasta la llegada del Pato Donald- tiene sobre sus espaldas la carga de convencer a la opinión pública y cambiar su orientación. Una tarea poco sencilla para un partido que llegó al poder enarbolando la bandera anti-OTAN" $"$.

Dicha tarea se realizó tanto a nivel institucional como personal. A nivel institucional el PSOE elaboró un documento titulado "Propuesta de una política de paz y seguridad", en el que se optaba por la permanencia bajo una serie de condiciones como la no incorporación a la estructura militar, la prohibición de instalación, almacenamiento o tránsito de armamento nuclear por nuestro territorio y la reducción de la presencia norteamericana. Por otra parte, a finales de año comenzó la segunda ronda de negociaciones con los Estados Unidos para la reducción de la presencia militar en España, lo que fue interpretado por ciertos sectores políticos y de la opinión pública como una contrapartida del Gobierno a sus electores a cambio de permanecer en una organización que muchos de ellos rechazaban. A nivel personal destacó el aumento del número de apariciones y declaraciones de Felipe González en los medios de comunicación a favor de la permanencia. Como muestra de su estrategia, valgan las declaraciones que realizó el presidente en una entrevista concedida a El País el 17 de noviembre de 1985 y que citamos por su importancia en contraste con la postura que había defendido cuatro años antes: "Creo que los intereses de España se defienden mejor permaneciendo en la Alianza. Nuestra anterior valoración sobre la Alianza y sobre su funcionamiento no era correcta (...) En la Alianza, de verdad, están los países que tienen mayor ejercicio de la soberanía popular del mundo, mayor nivel de desarrollo económico, de democracia, de libertades y de respeto a los derechos humanos, y mayor nivel de paz" ${ }^{\prime 61}$.

Para defender su postura, en esta entrevista González argumentaba que la salida de la OTAN impediría a España el acceso a tecnología importante, obligaría a mantener la vinculación bilateral con Estados Unidos y provocaría la desconfianza de los aliados europeos.

Declarada públicamente su postura ante la opinión española, el presidente concentró su discurso en tres aspectos convincentes para su electorado:

\footnotetext{
${ }^{58}$ Sin embargo, el decreto de convocatoria del referéndum no fue aprobado por el Consejo de Ministros hasta el 31 de enero de 1986, y por el Congreso de los Diputados hasta el 5 de febrero.

59 "El 63\% de los españoles desea el referéndum sobre la Alianza Atlántica”, El País, 3 de noviembre de 1985.

${ }^{60}$ Aguirre, Mariano: "España: seguridad, defensa y la OTAN", Revista de Estudios Internacionales, vol. VII, $\mathrm{n}^{\circ} 1$ (enero-marzo 1986), p. 50.

${ }^{61}$ Cebrián, Juan L.: "Entrevista de El País al presidente del Gobierno: «He perdido la libertad para que los demás la tengan», afirma Felipe González”, El País, 17 de noviembre de 1985.
} 
1. El cumplimiento del compromiso de celebrar el referéndum.

2. Las consecuencias negativas que para el Gobierno tendría un resultado negativo.

3. Las repercusiones a nivel internacional de la salida de la Alianza: el aislamiento respecto del mundo occidental, el retraso tecnológico, los riesgos impredecibles de una actitud contraria a los bloque militares o el desprestigio internacional.

Como resultado de los esfuerzos del Gobierno se produjo un giro en la opinión de buena parte del electorado, lo que se reflejó en una encuesta realizada por el CIS en febrero y que mostraba una notable división de la opinión pública (32\% a favor de la permanencia, $32 \%$ en contra y $36 \%$ de indecisos) ${ }^{62}$. Esta división alcanzó también a las distintas fuerzas políticas, como se puso de relieve en el Debate sobre la Política de Paz y Seguridad, celebrado los días 4 y 5 de febrero de 1986, en el que los partidos de la oposición rehusaron apoyar al Gobierno.

El 7 de febrero de 1986 se publicó en el Boletín Oficial del Estado el Real Decreto por el que se sometía a referéndum la permanencia en la Alianza ${ }^{63}$. En su texto se hacía referencia a la división de la opinión pública y de las fuerzas políticas que había provocado la adhesión de España a la OTAN en 1982, lo que había impedido alcanzar el necesario respaldo mayoritario de la sociedad. En contraposición con aquel momento, se señalaba un nuevo periodo histórico marcado por el reciente ingreso en la CEE y por la voluntad de compartir el futuro con el resto de las naciones democráticas europeas. En este nuevo contexto se daban las condiciones necesarias para someter a referéndum una decisión política de especial trascendencia. A tal objeto, y en base al artículo 92.2 de la Constitución, se fijaba la celebración de un referéndum de carácter consultivo en el que se plantearía a los electores el siguiente texto:

"El Gobierno considera conveniente, para los intereses nacionales, que España permanezca en la Alianza Atlántica, y acuerda que dicha permanencia se establezca en los siguientes términos:

1. La participación de España en la Alianza no incluirá su incorporación a la estructura militar integrada.

$2^{\circ}$. Se mantendrá la prohibición de instalar, almacenar o introducir armamento nuclear en territorio español.

3. Se procederá a la reducción progresiva de la presencia militar de los Estados Unidos en España",64.

La decisión objeto del referéndum quedó formulada de la siguiente manera: “¿Considera conveniente para España permanecer en la Alianza Atlántica en los términos acordados por el Gobierno de la Nación?".

\footnotetext{
${ }^{62}$ Rodrigo, op. cit., p. 99.

${ }^{63}$ Real Decreto 214/1986, de 6 de febrero, por el que se somete a referéndum de la Nación la decisión política del Gobierno en relación con la Alianza Atlántica, Boletín Oficial del Estado, núm. 33, de 7 febrero 1986, pp. 5072-5073.

${ }^{64}$ Ibid.
} 


\section{Opiniones sobre el referéndum}

Apenas un mes antes del referéndum el clima público y político del país se caracterizaba por la confrontación y la diversidad de opiniones. Una vez descrita la actitud del Gobierno, analizaremos brevemente la postura y reacciones de diversos grupos e instituciones ante la campaña del referéndum, así como la opinión de la sociedad española, lo que ayudará a explicar los resultados finales de la consulta.

\subsection{Las organizaciones anti-OTAN}

La postura contraria a la permanencia estuvo capitaneada principalmente por la Mesa por el Referéndum, la Plataforma Cívica para la Salida de la OTAN y la Coordinadora Estatal de Organizaciones Pacifistas (CEOP), integradas por una variedad de organizaciones sindicales, asociaciones civiles, colectivos y movimientos ecologistas y pacifistas ${ }^{65}$. Podemos resumir su postura en una serie de reivindicaciones y argumentos contrarios a la permanencia, entre ellos:

$1^{\circ}$. Defensa de la paz, desarme y neutralidad de España ante la política de bloques.

$2^{\circ}$. La presencia en la OTAN aumenta el peligro de guerra, al reforzar los bloques militares.

$3^{\circ}$. Aumenta el peligro de instalación de armamento nuclear en España.

$4^{\text {o }}$. Restringe la capacidad de maniobra de España en asuntos internacionales, especialmente en el Tercer Mundo.

$5^{\circ}$. Favorece la industria armamentística en detrimento de otras más necesarias.

$6^{\circ}$. Incrementa los gastos militares.

$7^{\circ}$. Cumplimiento del compromiso del Gobierno de celebrar el referéndum sobre la permanencia.

\subsection{Las fuerzas políticas}

Entre los partidos políticos hubo diversidad de opiniones y posiciones. Obviaremos en este apartado la postura de PSOE y UCD por haber sido abordada ya en este trabajo. Por su parte, el nuevo partido de Adolfo Suárez (Centro Democrático Social) se mostró favorable a la permanencia en la OTAN.

La postura del Partido Comunista había sido siempre claramente antiatlantista y antinorteamericana, planteando como metas en política exterior el no alineamiento en bloques militares, el impulso al ingreso en la CEE y el fomento de las relaciones internacionales con los países mediterráneos, el mundo árabe e Iberoamérica. Ya en su programa electoral de 1979 el PCE defendió una política de no alineamiento contraria a la adhesión; y en el debate de investidura de Calvo Sotelo, Santiago Carrillo, declaró que había oído en las palabras del

\footnotetext{
${ }^{65}$ Véase Val Cid, op. cit., pp. 126-129.
} 
presidente "la voz del Departamento de Estado" norteamericano ${ }^{66}$. Producido el ingreso, en la campaña electoral de 1982 se fijó como objetivo la convocatoria del referéndum en el plazo de seis meses, junto con otras medidas complementarias como la congelación de las negociaciones para la adhesión, la desnuclearización de España, la recuperación de la soberanía sobre Gibraltar y la no renovación del tratado bilateral con Estados Unidos.

Ante el referéndum de 1986 el PCE radicalizó su postura, participando activamente en las movilizaciones de la sociedad española y utilizando argumentos como la denuncia de la política de bloques y del imperialismo norteamericano, el aumento del riesgo de conflictos y de crisis nucleares en nuestro territorio, la carrera de armamento y sus elevados costes económicos. Con ese objetivo presentó un documento titulado "La paz es posible. Una propuesta de política exterior y de defensa fuera de la OTAN", que propugnaba una alternativa de defensa integrada en un marco global de neutralidad en política exterior.

Por su parte, Alianza Popular (AP) siempre había hecho gala de una vocación claramente atlantista. En su programa electoral de 1979, AP reclamó un debate inmediato con el fin de conseguir una inmediata integración en la OTAN como alternativa a la relación bilateral con los Estados Unidos, a la que consideraban impopular. La integración en la Alianza se justificó entonces en base a dos tipos de argumentos. Por un lado, argumentos de carácter ideológicos como el rechazo del neutralismo y del no alineamiento por ser una opción utópica, la necesidad de pertenecer al mundo occidental, y las ventajas de una relación multilateral con la OTAN. Por otro lado se esgrimieron argumentos relacionados con la política interior, entre los que destacaban la mejora y modernización de las FAS, la salvaguarda del sistema democrático, la obtención de garantías de defensa en caso de agresión del Pacto de Varsovia, la posibilidad de resolver el contencioso sobre Gibraltar y otros beneficios económicos, científicos, sociales, industriales y tecnológicos.

A partir de 1982, AP se mostró partidaria de la integración completa en la estructura militar, dejando en segundo plano la adhesión a la CEE y la resolución del conflicto de Gibraltar. Esta línea de actuación se vio reflejada tanto en su programa electoral de 1982 como en su VI Congreso, celebrado en enero de 1984. El 11 de diciembre de 1985, a pocos meses del referéndum y ya como Coalición Popular (CP) tras unirse con el Partido Demócrata Popular y el Partido Liberal, esta voluntad de conseguir la integración total se concretó en una Declaración Conjunta en la que se solicitaba la cancelación del referéndum, aduciendo intereses partidistas del Gobierno del PSOE y las consecuencias negativas para el sistema político español. En dicha declaración se advertía que, en caso de celebrarse la consulta, no participaría en la misma. Consecuentemente y con la intención de perjudicar al Gobierno, finalmente CP recomendó la abstención a sus votantes; actitud que fue criticada no sólo por el Gobierno y sus propios votantes, sino también por los representantes de los países aliados y los partidos conservadores europeos.

En último lugar, entre los partidos nacionalistas, pro atlantistas de tradición, predominó la ambigüedad e indefinición. En diciembre de 1985, Convergencia i Unió (CiU) presentó ante el Parlamento una moción a favor de la permanencia de España en la OTAN, que consiguió el apoyo de la oposición de derechas; sin embargo dio libertad de voto a sus electores. Por su parte, dentro del Partido Nacionalista Vasco (PNV) hubo posturas contrarias como la de Xabier Arzalluz,-favorable al sí- y la de Carlos Garaikoetxea, partidario del no.

\footnotetext{
${ }^{66}$ Calvo Sotelo y del Campo, op. cit., p. 68.
} 


\subsection{Los medios de comunicación}

En este apartado esbozaremos la actitud adoptada por los diferentes medios respecto a la conveniencia de la convocatoria del referéndum, sus consecuencias políticas y la línea editorial seguida al respecto ${ }^{67}$.

Ante la conveniencia del referéndum se pueden distinguir tres actitudes diferenciadas. La clara mayoría de los medios de comunicación, encabezados por los diarios $A B C, Y a, L a$ Vanguardia y Diario 16, se mostraron abiertamente en contra. La cadena SER también se manifestó en este sentido aunque más discreta y subliminalmente. Otros diarios mantuvieron una postura ambigua, como El Periódico de Barcelona, que lo calificó de acierto moral pero de error político. Por último, una minoría de los medios se mostró a favor de la celebración del referéndum, entre ellos el diario El País y algunos columnistas de la cadena Zeta.

En cuanto a las consecuencias existía la opinión generalizada por parte de todos los medios sobre las repercusiones negativas del referéndum para algunas figuras políticas como el presidente González y el presidente de CP, Manuel Fraga, por su postura abstencionista, calificada por la opinión pública como voto de castigo al Gobierno y poco solidaria por los países miembros de la Alianza.

Finalmente, las líneas editoriales fueron muy diversas. La Vanguardia, que había desaconsejado en un principio la celebración del referéndum y mostrado su disgusto por la convocatoria, dio un giro radical y solicitó encarecidamente el voto afirmativo. Por su parte, El País, que había mantenido una actitud crítica hacia el ingreso en la OTAN durante los gobiernos de UCD, modificó su actitud durante el gobierno socialista, pasando de la neutralidad a una posición favorable al sí, llegando a afirmar que el voto negativo podría suscitar tensiones institucionales. $A B C$ y la revista Época defendieron la abstención, en tanto que El Periódico y $Y a$ mantuvieron una postura ambigua o intermedia, aunque de distinta forma. $Y a$ pareció inclinarse por el sí, aunque hizo un llamamiento a la reflexión sobre el sentido del voto dadas las posibles consecuencias del referéndum. Por su parte, El Periódico mostró una actitud más neutra, exponiendo las razones para el sí y para el no, sin pronunciarse salvo en el carácter vinculante del referéndum. Por último, y por distintas motivaciones políticas, diarios tan opuestos como El Alcázar y Mundo Obrero defendieron denodadamente el no.

Mención especial merece el cambio de postura de Radio Televisión Española (RTVE), tradicionalmente anti OTAN. Durante el gobierno de Calvo Sotelo y los inicios del gobierno socialista, Televisión Española había criticado abiertamente a la Organización, acusándola de pasividad ante los golpes de estado de Grecia y Turquía, y resaltando las consecuencias negativas de la adhesión, como el aumento de riesgo de conflicto y la nuclearización del país $^{68}$. Sin embargo, siguiendo la línea marcada por el gobierno socialista, RTVE se mostró claramente partidaria del sí en la campaña del referéndum.

\footnotetext{
${ }^{67}$ Para un análisis más amplio y detallado de este tema, véase Arias, Inocencio F. (1986): "Los medios de información españoles en las campañas de la OTAN", en España dentro de la Alianza Atlántica. Instituto de Cultura Iberoamericana, Madrid, pp. 127-143.

${ }^{68}$ En su discurso de ingreso en la Academia de Ciencias Morales y Políticas, titulado "Sobre la transición exterior", Calvo Sotelo relata un hecho esclarecedor al respecto. En otoño de 1981, poco antes del debate parlamentario sobre el ingreso en la OTAN, la primera cadena emitió una crónica informativa sobre la Alianza en el que una voz en off leía los artículos del Tratado de Washington mientras se proyectaban de fondo “imágenes terroríficas de guerra", muerte y desolación.
} 


\subsection{La Iglesia Católica}

En la actitud de la Iglesia católica podemos encontrar dos líneas diferenciadas ${ }^{69}$ :

a) La postura ambigua de la Conferencia Episcopal, sustentada en las dudas acerca de la capacidad de los electores de pronunciarse sobre decisiones políticas de tal importancia. Esta postura se reflejó en comunicado emitido el 14 de febrero de 1986 en el que se aludía a la complejidad de la formulación de la pregunta, a la falta de información del electorado sobre las consecuencias económicas, militares y políticas de los resultados, así como a las interpretaciones y valoraciones que el Gobierno pudiera hacer de los resultados del referéndum.

b) La postura claramente contraria a la permanencia en la OTAN de los obispos de Pamplona y el País Vasco, reflejada en un documento emitido en diciembre de 1985 por los Secretariados Sociales de dichas diócesis y en el que se acusaba al Gobierno de actuar bajo presiones de los países aliados y de exagerar las consecuencias negativas de la salida de la organización. En dicho documento se proponían entre otras medidas la celebración de un debate parlamentario sobre política exterior, la convocatoria inmediata de un referéndum de carácter vinculante y la necesidad de optar por la neutralidad como única medida para conseguir la paz mundial.

\subsection{Los países aliados}

La reacción de los países miembros de la OTAN ante la convocatoria del referéndum no fue demasiado airada, por ser una medida esperada que la diplomacia española había dejado clara durante los cuatro años que España llevaba dentro de la Alianza. Como declaró en vísperas del referéndum su secretario general Lord Carrington, la OTAN era una organización abierta y flexible, en la cual cada país miembro podía comer a la carta y elegir el menú que más le conviniera a su $\operatorname{dieta}^{70}$.

Sin embargo, la actitud del Gobierno español al plantear las condiciones de la permanencia creó cierta imagen de falta de solidaridad en los aliados. En primer lugar, porque la no integración podía suponer para la OTAN una generalización del precedente de Francia y alentar a otros miembros a actuar de la misma manera. Además, la negativa española al almacenamiento, instalación y tránsito de armamento nuclear en su territorio era claramente contraria a la estrategia de disuasión de la OTAN. Por último, la reducción de la presencia norteamericana en España obligaba a otras naciones a aumentar su aportación a la defensa colectiva. Como es de suponer, estas dos últimas condiciones provocaron el lógico descontento del gobierno norteamericano.

\subsection{La opinión pública}

La opinión pública española ha mostrado tradicionalmente un profundo desconocimiento y desinterés por los asuntos internacionales. Durante la transición, este desconocimiento se

\footnotetext{
${ }^{69}$ Véase: Val Cid, op. cit., pp. 129-131.

70 "La nueva dimensión de una antigua alianza", Revista española de defensa, Madrid, Ministerio de Defensa, DRISDE, $\mathrm{n}^{\circ} 1$ (marzo 1988), p. 36.
} 
combinaba con un casi exclusivo interés en las cuestiones de política interior ${ }^{71}$, en consonancia con la actitud de sus dirigentes políticos. De este modo, no es de extrañar que la opinión pública mostrara una ignorancia completa tanto por la historia como por los objetivos y finalidades de la Alianza. Según la encuesta del CIS sobre relaciones internacionales de octubre de 1978 sólo un $24 \%$ de los españoles conocía alguna de las finalidades de la OTAN, y era una amplia mayoría (68\%) la que declaraba no conocer ninguna ${ }^{72}$. Por su parte, a la pregunta "¿Personalmente sería muy partidario, bastante, poco o nada partidario de la entrada de España en la OTAN?" un 55 \% de los encuestados respondió "no sabe",73, lo que indica el escaso interés que la adhesión a la OTAN despertaba en la opinión pública ${ }^{74}$. Del mismo modo, los resultados del Estudio del CIS sobre relaciones exteriores de diciembre de 1979 indicaban que los temas de política exterior que más preocupaban a los españoles en aquel momento eran, por este orden, el ingreso en el Mercado Común (50\%), la recuperación de Gibraltar y las relaciones con Iberoamérica (ambas con el $32 \%$ ) y la presencia de España en las organizaciones internacionales (26\%). Las relaciones con la OTAN era el tema que menor preocupación suscitaba entre los encuestados $(7 \%)^{75}$.

Sin ánimos de profundizar en las causas de este desconocimiento y desinterés de la opinión pública por los temas de política exterior en general y por la cuestión de la OTAN en particular, podemos señalar al respecto argumentos como la reminiscencia del aislamiento internacional de la dictadura, ciertas connotaciones antimilistaristas relacionadas con el apoyo de las FAS al régimen franquista o cierto sentimiento antinorteamericano, que fue explotado y alentado frecuentemente por los partidos de izquierda durante la campaña antiOTAN de 1981 y que iba a condicionar de manera importante las relaciones entre España y la OTAN ${ }^{76}$. Tampoco los distintos gobiernos y partidos políticos de aquella época mostraban gran interés en fomentar el conocimiento de estos asuntos.

Lo cierto es que esta falta de información y desconocimiento de la cuestión convirtió a la opinión pública española en fácilmente manipulable y maleable y, por tanto, vulnerable a campañas políticas guiadas por intereses oportunistas y electoralistas. Es lo que se ha denominado "volatilidad" de la opinión pública española en cuestiones de política exterior, y

\footnotetext{
${ }^{71}$ Calvo Sotelo y del Campo, op. cit., p. 61.

${ }^{72}$ Centro de Investigaciones Sociológicas, op. cit., pp. 197-198.

${ }^{73}$ Ibid., pp. 199-200.

${ }^{74}$ Calvo Sotelo y del Campo, op. cit., p. 64.

${ }^{75}$ Centro de Investigaciones Sociológicas, op. cit., pp. 208-209. La pregunta objeto de análisis en este caso era: "Le voy a señalar una serie de temas de la política exterior de España. Quiero que me diga los tres que considera más importante: 1) Relaciones con Iberoamérica. 2) Recuperación de Gibraltar. 3) Entrada en el Mercado Común. 4) Relaciones con los países comunistas. 5) Fortalecimiento de relaciones con el Tercer Mundo. 6) Presencia de España en organizaciones internacionales. 7) Relaciones con la OTAN. 8) Política de buena vecindad con Francia y Portugal. 9) Relaciones cordiales con nuestros vecinos del Norte de África". Como muestra del desinterés en cuestiones de política exterior al que antes aludíamos resulta significativo destacar que un $34 \%$ de los encuestados respondieron a esta pregunta "no sabe/no contesta".

${ }^{76}$ Como recoge Bray, op. cit., pp. 170-171, una encuesta realizada en 1988 señalaba que Estados Unidos constituía para los españoles, en mayor medida que cualquier otro país a excepción de Marruecos, una amenaza potencial para la seguridad del país. En palabras del que fuera secretario de Relaciones Internacionales de la Comisión Ejecutiva del PSOE desde 1975 a 1979, Luis Yáñez, op. cit., p. 325: "Para los españoles (...) los norteamericanos eran sinónimos de defensores y apuntaladores de la dictadura (...) era difícil presentar a los Estados Unidos como paladín de la libertad y como amigo de España, y al ser el líder hegemónico de la OTAN, tampoco esta organización podía aspirar a tener buena imagen entre nosotros". Para un análisis más detallado de la mentalidad española en los asuntos relacionados con la política exterior véase Portero, Florentino: "La política de seguridad española”, Cuenta y Razón, no 38 (julio/agosto 1988), pp. 51-54.
} 
explicaría el cambio de la opinión española tanto con respecto a la adhesión a la OTAN en 1981 , como con respecto a la permanencia en $1986^{77}$.

En la siguiente tabla se presenta la evolución de la actitud de la opinión pública ante el ingreso en la $\mathrm{OTAN}^{78}$ :

Tabla 1. Evolución de la actitud de la opinión pública ante el ingreso en la OTAN

\begin{tabular}{|c|c|c|c|c|c|c|c|c|}
\hline & Junio 1975 & Enero 1976 & $\begin{array}{c}\text { Octubre } \\
1978\end{array}$ & Julio 1979 & Julio 1981 & $\begin{array}{c}\text { Septiembre } \\
1981\end{array}$ & Marzo 1983 & Junio 1983 \\
\hline Partidarios & $57 \%$ & $40 \%$ & $27 \%$ & $28 \%$ & $20 \%$ & $13 \%$ & $13 \%$ & $17 \%$ \\
\hline $\begin{array}{l}\text { Poco o nada } \\
\text { partidarios }\end{array}$ & $24 \%$ & $17 \%$ & $15 \%$ & $26 \%$ & $35 \%$ & $43 \%$ & $57 \%$ & $56 \%$ \\
\hline $\begin{array}{l}\text { No sabe, no } \\
\text { contesta }\end{array}$ & $19 \%$ & $43 \%$ & $58 \%$ & $46 \%$ & $45 \%$ & $44 \%$ & $30 \%$ & $27 \%$ \\
\hline Total & $100 \%$ & $100 \%$ & $100 \%$ & $100 \%$ & $100 \%$ & $100 \%$ & $100 \%$ & $100 \%$ \\
\hline
\end{tabular}

Fuente: Centro de Investigaciones Sociológicas

Podemos observar la tendencia decreciente que sigue el porcentaje de partidarios del ingreso en la Alianza desde 1975 (57\%) hasta 1981, fecha en que el gobierno de UCD planteó ante el Parlamento la integración formal de España en la OTAN (13\%). Estos datos se explican por la influencia de la campaña anti-OTAN puesta en marcha por el PSOE en $1981^{79}$, una campaña que ha sido considerada a menudo como incoherente, demagógica e irresponsable; pero que el mismo ex presidente Calvo Sotelo calificó de hábil, eficaz, tenaz e inteligente ${ }^{80}$. Caso contrario ocurrió de cara al referéndum de 1986, en el que la campaña del gobierno a favor del sí logró en buena parte modificar la opinión pública española, que unos meses antes del referéndum se mostraba mayoritariamente en contra de la permanencia en la Alianza.

La actitud del PSOE en ambos casos ha sido descrita como un claro ejemplo de transformación radical de su discurso político, de bombardeo y desinformación de la opinión pública, mediante el cual se trató de convencer al público para que votara en contra de sus más íntimas convicciones ${ }^{81}$.

Para explicar el triunfo mayoritario del sí el 12 de marzo de 1986 se han señalado diversas causas ${ }^{82}$ :

a) El apoyo recibido por parte del electorado de Coalición Popular, que desobedeció las recomendaciones abstencionistas de su partido.

\footnotetext{
${ }^{77}$ Calvo Sotelo y del Campo, op. cit., p. 65.

${ }^{78}$ Centro de Investigaciones Sociológicas, op. cit., pp. 188, 193-194.

${ }^{79}$ Calvo Sotelo y del Campo, op. cit., p. 70.

${ }^{80}$ Ibid, pp. 65 y 70 .

${ }^{81}$ Ibid, p. 73.

${ }^{82}$ Arias, op. cit., pp. 136-138
} 
b) Cierto sector de la izquierda partidario del no percibió que una derrota en el referéndum hubiera dañado gravemente al PSOE, suponiendo la posibilidad de una posterior derrota en las elecciones generales. En este sentido, muchos votantes de la izquierda fueron conscientes de que votar en contra de la OTAN hubiera obligado a dimitir al Gobierno de González ${ }^{83}$.

c) El efecto de los sondeos electorales, que pronosticaban un triunfo insalvable del no forzó a un número considerable de votantes que no pensaban votar a acudir a las urnas, cambiando crucialmente el sentido del voto.

d) La influencia de ciertos medios de comunicación, fundamentalmente de RTVE, a la que la oposición acusó de oficialista y de haber manipulado sin disimulo la campaña a favor del sí.

e) El esfuerzo personal del presidente González, multiplicando sus apariciones públicas, y la habilidad de su discurso centrado en las consecuencias negativas de una victoria del $n o$, tanto para el Gobierno como para la política exterior española. También se ha destacado a este respecto la entrega y el cambio de opinión del vicepresidente Guerra.

\section{Epílogo. El modelo español}

El día 12 de marzo se celebró la consulta, obteniéndose contra todos los pronósticos, los siguientes resultados: sobre un número total de 29.025.494 electores, se contabilizaron 17.246.458 (59,42\%) de votos emitidos: 9.054 .509 votos a favor $(52,49 \%), 6.872 .421$ votos en contra $(39,8 \%), 1.127 .673$ votos en blanco $(6,53 \%)$ y 191.855 votos nulos $(1,11 \%)$.

El modelo de participación español en la OTAN derivó de las condiciones impuestas por el Gobierno a la permanencia en la Alianza, refrendadas en el referéndum. Antes de pasar a describir brevemente el modelo español, conviene señalar algunas consideraciones sobre estas condiciones, haciéndonos eco de las críticas que realizan algunos autores en el sentido de que dichas condiciones estaban trucadas, eran falsas $u$ ocultaban un objetivo meramente propagandístico $^{84}$.

En primer lugar, la desnuclearización del país era innecesaria, ya que -como hemos señalado anteriormente- ésta constituía una de las condiciones mediante las cuales las Cortes Generales autorizaron la adhesión a la OTAN en 1981. Por otro lado, el Convenio hispanonorteamericano sobre Colaboración para la Defensa, firmado por ambos países en diciembre de 1988, supeditaba la instalación, almacenamiento o introducción de armamento nuclear en territorio español al acuerdo del Gobierno español ${ }^{85}$; prohibiendo además el sobrevuelo del espacio aéreo español de aeronaves con armamento y material nuclear a bordo ${ }^{86}$. Sin embargo, dicho Convenio eximía tanto a buques como a aeronaves norteamericanas

\footnotetext{
${ }^{83}$ Burns, op. cit., p. 104.

${ }^{84}$ Véase la opinión del primer embajador español en la OTAN, Javier Rupérez, op. cit., p. 20.

${ }^{85}$ Artículo 11.2 del Convenio entre el Reino de España y los Estados Unidos de América sobre Cooperación para la Defensa, anejos y canje de notas anejas al mismo. Boletín Oficial del Estado, núm. 108, de 6 de mayo de 1989 , p. 13325.

${ }^{86}$ Nota del Ministro de Exteriores español, Francisco Fernández Ordoñez, al Embajador de los EE.UU en España, Richard Bartholomew, de fecha 1 de diciembre de 1989. Aneja al Convenio entre el Reino de España y los Estados Unidos de América sobre Cooperación para la Defensa, op. cit., p. 13345.
} 
desplegadas en España de ser inspeccionadas, lo que en la práctica permitía la introducción y tránsito de armamento nuclear por España ${ }^{87}$.

En cuanto a la reducción de fuerzas norteamericanas se limitó a la salida del Ala Táctica 401 (cazas F-16) de la base aérea de Torrejón de Ardoz, una propuesta planteada por España el 10 de julio de 1986 y a la que Estados Unidos tardó seis meses en responder, haciéndolo el 3 de febrero de 1987 con una contrapropuesta que consistía en trasladar dicha unidad a la Base Aérea de Morón de la Frontera, sin retirarla por tanto de territorio nacional. El 15 de enero ambos países firmaban una Declaración Conjunta en la que se anunciaba la salida de los F-16 de España, medida que fue refrendada en el Convenio de Cooperación hispano-norteamericano en materia de Defensa, aunque otorgando un plazo de tres años a partir de su fecha de entrada en vigor para llevarla a cabo ${ }^{88}$. Por tanto, pese a que en medios diplomáticos españoles esta reducción de la presencia militar norteamericana se calificó de "sustancial" 89 , apenas afectó a unos cientos de militares norteamericanos, sin producirse la expulsión masiva que algunos esperaban ${ }^{90}$.

Finalmente, citando a Javier Rupérez, la no incorporación a la estructura militar integrada de la OTAN se tradujo en una "no participación" en la estructura de mandos integrados, lo que no es más que la parte final del proceso de integración ${ }^{91}$.

Con todo, dos días después del referéndum, el ministro de Exteriores Fernández Ordóñez comunicó al secretario general de la Alianza y a los ministros de Defensa y Exteriores aliados, dichos resultados y las condiciones bajo las que España permanecería en la OTAN. A partir de ese momento, el Gobierno elaboró nueve principios generales, que constituían las bases generales para la participación española en la OTAN y su contribución a la defensa común, que fueron presentados inicialmente por España en la sesión del Consejo Atlántico del 20 de mayo y posteriormente en las sesiones ministeriales de primavera del Comité de Planes de la Defensa. Dichos principios incluían, entre otros aspectos, la no participación en la estructura militar integrada, el planeamiento coordinado de la defensa, la contribución militar española y la participación en las cargas financieras de la Organización ${ }^{92}$. A partir de ese momento se iniciaron una serie de consultas y conversaciones preliminares entre una delegación española, compuesta por representantes de los ministerios de Defensa y Exteriores y presidida por el embajador Jaime de Ojeda; y una comisión de la OTAN,

\footnotetext{
${ }^{87}$ Artículo 25.1 del Convenio entre el Reino de España y los Estados Unidos de América sobre Cooperación para la Defensa, op. cit., p. 13328: "Las aeronaves de las Fuerzas de los Estados Unidos de América desplegadas en España con carácter permanente o rotativo, dentro del nivel de fuerzas acordado, pueden sobrevolar, entrar y salir del espacio aéreo español y utilizar las bases y establecimientos especificados en el anejo 2 del presente Convenio, sin más requisito que el cumplimiento de la reglamentación española de circulación aérea (...)". Artículo $7 \mathrm{del}$ Anejo 3 (Normas complementarias sobre escalas de buques) del Convenio entre el Reino de España y los Estados Unidos de América sobre Cooperación para la Defensa, op. cit., p. 13336: “Ambos Gobiernos otorgarán las autorizaciones reguladas en el presente anejo sin solicitar información sobre el tipo de armas a bordo de los buques"; Artículo 9.3: "Los buques de la Armada española y los buques de las Fuerzas de los Estados Unidos de América estarán exentos de inspecciones, incluidas las de aduanas y sanidad” (ibid.).

${ }^{88}$ Artículo 1.3 de la Nota 420/12, de 1 de diciembre de 1998, del embajador español Máximo Cajal a su homónimo norteamericano, Richard Bartholomew. Convenio entre el Reino de España y los Estados Unidos de América sobre Cooperación para la Defensa, op. cit., p. 13343.

${ }^{89}$ Cajal, Máximo: "El Convenio Hispano-norteamericano de Cooperación para la Defensa de 1.12.1988", UNISCI Discussion Papers, no 3 (octubre 2003), en http://www.ucm.es/info/unisci.

${ }^{90}$ Rupérez, 1997, op. cit., p. 20.

91 Ibid.

92 Sánchez Méndez, José: “La década de los 80, nuestra adhesión a la Alianza Atlántica. Los acuerdos de coordinación: modelo español de participación en la OTAN", Revista de aeronáutica y astronáutica, Madrid, Ministerio del Aire, no 590 (enero-febrero 1990), p. 58.
} 
encabezada por el secretario general adjunto de Planes y Política de Defensa Michael Bell, y que incluía a miembros del Secretariado Internacional, del Cuartel General Aliado en Europa (SHAPE), del mando supremo aliado del Atlántico (SACLANT) y del Estado Mayor Internacional $^{93}$. Dado los antecedentes de Francia, estas conversaciones estuvieron marcadas inicialmente por las dudas aliadas sobre la aportación real y efectiva de España fuera de la estructura integrada de mandos ${ }^{94}$. Sin embargo la flexibilidad de los aliados hizo posible llegar a un acuerdo, lo que permitió al Gobierno español elaborar una serie de propuestas sobre la contribución de España a la defensa común de la Alianza.

En base a dichas propuestas, el 18 de enero de 1988 el embajador Ojeda dirigió al secretario general de la OTAN una carta en la que se concretaban los cometidos de las FAS españolas y se articulaba su participación en la defensa común a través de una serie de acuerdos de coordinación entre mandos españoles y aliados ${ }^{95}$. El texto incluía las seis áreas en las que España deseaba coordinar sus actividades militares con la OTAN, los conocidos como los seis puntos del modelo español:

1. Impedir la ocupación del territorio español.

2. Operaciones aéreas y navales en el Atlántico Oriental.

3. Control del Estrecho de Gibraltar y sus accesos.

4. Operaciones aéreas y navales en el Mediterráneo Occidental.

5. Control del espacio aéreo y defensa aérea en la zona de responsabilidad española, y cooperación en las áreas adyacentes.

6. Utilización del territorio español como área de tránsito, apoyo y logística de retaguardia ${ }^{96}$.

El 8 de febrero el Comité de Planes de Defensa aprobó el procedimiento para la elaboración de los acuerdos de coordinación que regularía la contribución militar española a la defensa común aliada fuera de la estructura militar integrada. Días después el Consejo Atlántico aceptó dichas propuestas y el Comité de Planes de Defensa encargó al presidente del Comité Militar, general Altenburg, que junto a las autoridades españolas se elaboraran las Directrices Generales para el Desarrollo de los Acuerdos de Coordinación entre los mandos españoles y aliados $^{97}$. Estas Directrices quedaron plasmadas en el documento titulado MC-313, aprobado por el Comité Militar el 10 de noviembre y refrendado posteriormente tanto por el Comité de Planes de Defensa como por el Consejo Atlántico, el 1 y 8 de diciembre respectivamente.

\footnotetext{
${ }^{93}$ Ortiz, op. cit., p. 61.

${ }^{94}$ En 1966 Francia había abandonado la estructura integrada de mandos, retirando a sus representantes del Comité de Planes de Defensa y del Comité Militar, lo que había sido percibido por el resto de países aliados como una prueba de falta de solidaridad.

${ }^{95}$ El contenido de esta carta puede consultarse en Martínez-Esparza, Juan: "España en la Alianza: siete años después", Revista de aeronáutica y astronáutica, Madrid, Ministerio del Aire, no 580 (abril 1989), pp. 430-431.

96 "La nueva dimensión de una antigua alianza", Revista española de defensa, Madrid, Ministerio de Defensa, DRISDE, no 1 (marzo 1988), p. 36.

${ }^{97}$ Sánchez Méndez, op. cit., p. 61.
} 
El modelo español de participación, que combinaba "la no integración militar con una activa participación en la Alianza" 98 y que pareció satisfacer inicialmente tanto a políticos y diplomáticos como a militares, recibió pronto importantes críticas, entre las que podemos citar:

a) La no integración en la estructura militar de la OTAN limitaba la participación española en los procesos decisorios de la Alianza.

b) La negativa a la instalación, almacenamiento y tránsito de armamento nuclear en territorio nacional, así como la exigencia de reducción del personal militar norteamericano destacado en España creó la sensación de insolidaridad entre los países aliados, pues afectó a una de las principales finalidades de la Alianza como es la defensa común. Además, ello limitó el peso y la capacidad española de influir en sus aliados ${ }^{99}$.

c) España perdió la oportunidad de negociar la creación de un mando aliado de primer orden en territorio español y bajo mando propio, lo que hubiera reforzado la defensa del eje estratégico Baleares-Estrecho-Canarias, fundamental para los intereses defensivos nacionales. En el mismo sentido, la creación de un hipotético mando aliado bajo jurisdicción española hubiera permitido a nuestro país impulsar sus opciones de recuperar Gibraltar, al privar al Reino Unido del principal argumento esgrimido por los británicos para mantener la soberanía sobre el Peñón: asegurar un enclave fundamental para la defensa de Occidente ${ }^{100}$.

d) Finalmente, la negativa española a reconocer el mando aliado en Gibraltar (GIBMED) y a coordinarse con él planteaba problemas de eficacia operativa en la zona, afectando a la seguridad de un área estratégica importante para nuestro país.

\section{A modo de conclusión}

El proceso de adhesión de España a la OTAN, que culminó con el referéndum sobre la permanencia en la Alianza de 1986, fue un camino repleto de polémicas, obstáculos y contradicciones en el que jugaron un papel trascendental diversos elementos y actores. En primer lugar, el momento histórico en que se inició el proceso, la transición política desde una dictadura, que arrastraba la rémora del aislamiento a nivel internacional, a una joven democracia deseosa de integrarse en el mundo occidental y en sus organismos internacionales. En este proceso hay que destacar también la importancia de ciertos condicionantes geopolíticos derivados de la situación estratégica de nuestro país y su vinculación con el sistema defensivo europeo en base a los acuerdos de cooperación en materia militar con los Estados Unidos de 1953 y sus posteriores renovaciones.

Otro aspecto a considerar es el papel personal desempeñado por determinadas personalidades, fundamentalmente presidentes y ministros de asuntos exteriores de los distintos gobiernos en el poder, en unas ocasiones impulsando el ingreso en la OTAN, en otras demorándolo o paralizándolo. En cuanto a lo primero, podemos citar el papel desempeñado por el ministro Oreja y el presidente Calvo Sotelo; en el segundo caso,

\footnotetext{
${ }^{98}$ Ortiz, op. cit., p. 60.

${ }^{99}$ Portero, op. cit., p. 53.

${ }^{100}$ Ibid.
} 
destacamos las figuras de Adolfo Suárez y Felipe González. A menudo, estas actitudes personales crearon polémica, controversias y tensiones no solo en el seno de sus respectivos partidos y ejecutivos, sino incluso en el clima político del momento.

A este último respecto es de destacar, como eje fundamental del proceso de adhesión en la OTAN, el radical cambio de actitud del PSOE, fruto de un planteamiento inicial inadecuado e incoherente de la cuestión y que puede explicarse por la falta de experiencia política de sus dirigentes, sobre todo en asuntos exteriores. En 1981 el PSOE se lanzó a una radical campaña antiOTAN, basada en argumentos catastrofistas y electoralistas y que se alimentó del desinterés y desconocimiento de la población española por las cuestiones de política exterior en general, y de la esencia y objetivos de la OTAN en particular, aprovechándose de una opinión pública fácilmente manipulable por intereses electoralistas. La introducción de la propuesta del referéndum en el programa electoral socialista de 1982 constituyó un grave error, tal como lo reconocerían posterior y públicamente numerosos dirigentes socialistas, incluidos los ex ministros Serra y Morán o el mismo Felipe González. La postura irreflexiva del gobierno socialista le iba a pasar factura pocos años después, al verse obligado a dar marcha atrás y convencer al mismo electorado de la conveniencia de permanecer en la Alianza.

Nos encontramos, por tanto, ante un claro ejemplo de contradicción en asuntos exteriores. Como lo sería en 1995 el nombramiento del jefe de la campaña antiOTAN del PSOE en 1981, Javier Solana, como secretario general de la Alianza. 